\title{
Tutoria: perspetiva de estudantes e professores de enfermagen
}

\author{
Maria-Margarida Sim-Sim, Maria-do-Céu Marques, Maria-dos-Anjos Frade \\ e Maria-Antónia Chora
}

\begin{abstract}
Resumo
Com o objetivo de avaliar o processo de tutoria, descreve-se a perceção dos estudantes e docentes da Escola Superior de Enfermagem São João de Deus (ESESDJ) da Universidade de Évora (UÉ) em Portugal. Aplicaram-se questionários de autopreenchimento a 146 discentes e 19 docentes. Trata-se de um estudo quantitativo, descritivo e transversal. Os resultados indicam que globalmente, os estudantes percebem a tutoria como um recurso positivo, reconhecem no tutor, um orientador válido no percurso de formação, que está disponível e é amigável. Os docentes identificam-se como figuras de recurso e procuram responder às necessidades dos estudantes. Como problemas principais dos estudantes, emergem a adaptação ao ritmo e gestão das tarefas académicas. Na perspetiva dos professores, a tutoria trouxe benefícios. Concluem ambos os grupos que o regime deve ser facultativo e apontam dois episódios semestrais como os necessários/suficientes.
\end{abstract}

Palavras chave: educação superior, estudantes de enfermagem, tutoria, precetoria, Portugal. 


\title{
Tutoría: perspectiva de los estudiantes y maestros de enfermería
}

\section{Resumen}

Con el objetivo de evaluar el proceso de tutoría, se describe la percepción de los estudiantes y docentes de la ESESDJ-UÉ. Se aplicaron cuestionarios de autocompletado a 146 estudiantes y 19 docentes. Se trata de un estudio cuantitativo, descriptivo y transversal. Los resultados indican que en general los estudiantes perciben la tutoría como un recurso positivo, reconocen en el tutor a un orientador válido en el trayecto de su formación, que está disponible y es amigable. Los docentes se identifican como figuras de recurso y buscan responder a las necesidades de los estudiantes. Como principales problemas de los estudiantes, emergen la adaptación al ritmo y administración de las tareas académicas. Desde la perspectiva de los maestros, la tutoría ha traído beneficios. Concluyen ambos grupos que el régimen debe ser facultativo y señalan dos eventos semestrales como los necesarios y/o suficientes.

Palabras clave: educación superior, estudiantes de enfermería, tutoría.

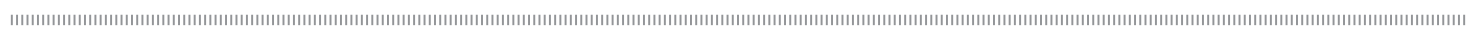

\section{Tutoring: Perspectives of student nurses and teachers}

\begin{abstract}
In order to assess the tutoring process they perception of students and teachers of the ESESDJ-UÉ is described. 146 students and 19 teachers filled out the questionnaires. It is a quantitative, descriptive and transversal study. The results indicate that generally students perceive tutoring as a positive resource; they acknowledge that teachers are valid counselors during their formation, who are available and friendly. Teachers identify themselves as a resource and strive to respond to the students needs. Adjustment to the rhythm and task management arise as main issues of the students. From the teachers' perspective tutoring is considered as beneficial. Both groups conclude that the system should be optional and point out that the half-yearly events are necessary and/or sufficient.
\end{abstract}

Key words: higher education, student nurses, tutorin. 


\section{Introdução}

O ensino de enfermagem em contexto clínico, detém uma experiência longa de tutoria, orientando ao estudante no âmbito do desenvolvimento humano, educativo, profissional (Ali e Panther, 2008; Gray e Smith, 2000; Carson e Carnwell, 2007). Para a União Europeia (UE), através da Diretiva 36/2005 de 7 de setembro, está previsto que o estudante aprenda, no contexto dos ensinos clínicos, "no seio de uma equipa e em contacto direto com um indivíduo em bom estado de saúde ou doente e/ou uma coletividade, a planear, dispensar e avaliar os cuidados de enfermagem globais requeridos, com base nos conhecimentos e competências adquiridas" (Comunidade Europeia, 2005: 41). As orientações da Diretiva 36/2005, relativamente ao ensino teórico de enfermagem, não mostram figuras tutoriais visíveis; contudo a documentação legal portuguesa (Dec-Lei 74/2006 e Dec-Lei 107/2008), ao instituir o Processo de Bolonha, transmite um novo paradigma, que orienta o ensino superior para a centralização no desenvolvimento dos estudantes, mais do que no exercício do professorado magistral clássico.

A organização dos estudos, terá que contar com flexibilidade curricular, nova organização do trabalho docente e discente, novas formas de avaliação e de regimes tutoriais, entre outros aspetos (Lima, 2006), de forma a privilegiar a ajuda ao estudante, nos contextos académico, pessoal e profissional (Boronat, Castaño e Ruiz, 2005).

\section{Revisão da literatura}

O tutor, na sua função de educador "é uma pessoa dotada de autoridade (auctoritas, capacidade de dar auge, de ajudar ao crescimento) porque com o seu modo de viver ensina a crescer em humanidade" (Carbajo, 2004: 140). A tutoria, segundo La Cruz, Campos e Hernández (2006) numa perspetiva de modelo integrador, consiste num processo sociocognoscitivo, personalizado, cuja finalidade é transformar os recém-chegados em indivíduos competentes, integrando-os na comunidade, gerando-se conhecimento e simultaneamente o seu reconhecimento como membro dessa área de profissional. Estes autores, referindo-se aos vários ciclos do ensino superior, identificam como papéis tutoriais centrais: a investigação, na medida da sustentação na evidência científica e gerar de conhecimento; a formação profissional, centrada no desenvolvimento do estudante; a docência, favorecendo ao estudante o domínio e capacidade de transmitir conhecimento; e a socialização, incorporando os tutorandos nas comunidades profissionais e de investigação. Boronat, Castaño e Ruiz (2005), falam de: a) tutoria como função legal, por prescrição aos docentes com exclusividade; b) tutoria como função académica, com carácter de assessoria a programas, facilitação de fontes bibliográficas, documentais e orientação de trabalhos; c) tutoria como função docente, traduzindo uma modalidade particular do exercício da docência, evidenciando-se na organização de seminários, acompanhamento de práticas, no seguimento de grupos de alunos; d) tutoria personalizada, que prevê a solicitação por parte do estudantes, de orientação a nível pessoal ou profissional, de acordo com as suas necessidades e expectativas; e) tutória colegial, na forma de agregado de docentes que segue grupos de alunos oferecendo seguimento em diversos âmbitos; f) tutoria virtual, que proporcionam ao aluno, assistência e ajuda em tempo imediato, diversificando as fontes de conhecimento. Consideram-se ainda outras formas tutoriais como: a) tutoria interpares (peer mentoring), referindo-se a uma metodologia de aproximação entre estudantes com finalidades de integração no meio académico, e b) a tutoria na figura do buddy, trazendo benefícios para os estudantes na medida da valorização curricular.

Algumas características do tutor ditam a aproximação ou afastamento do tutorando. Carbajo 
(2004, citando Gibb, 1961), refere que no diálogo educativo há atitudes do professor que colocam ao aluno na defensiva, tais como postura de juiz, obtenção de informações com fins de controlo, falta de cordialidade, distância e superioridade. Outras predispõem o aluno a abrir-se ao diálogo, nomeadamente aceitação, disponibilidade para ajudar a definir um problema, espontaneidade na expressão e autenticidade no comportamento, empatia, escuta e respeito pelas opiniões. Contudo algumas dificuldades são reconhecidas, face à multiplicidade dos papéis tutoriais, condições de trabalho e carreira. Lima (2006) interroga-se, entre outras, sobre as condições de atendimento de estudantes e a dignificação de um trabalho docente que não é contabilizado como tal.

A figura fundamental que justifica todo o processo é o estudante, documentando Veiga Simão, Flores, Fernandes e Figueira (2008), que algumas das experiências portuguesas são construídas com base na prática institucional concreta. Os contactos pretendem conhecer o pensamento do estudante, para que possa ser identificado o apoio necessário, no sentido de ajudá-lo a conhecer-se, a responsabilizar-se pelas decisões pessoais e escolares. A escuta ativa, o tempo de atenção na singularidade de cada aluno, a oferta de protagonismo ao estudante, são atitudes recomendáveis, repudiando-se os interrogatórios pois se assemelham a formulários a preencher para cumprir o atendimento. A finalidade da orientação tutorial não é individualizar, mas personalizar (Carbajo, 2004).

$\mathrm{Na}$ cultura institucional da Escola Superior de Enfermagem São João de Deus (ESESDJ) da Universidade de Évora (UÉ) em Portugal, a tutoria docente pré-graduada iniciou-se no ano letivo 2007-2008, através do Regulamento Específico (Capitulo VI), homologado em 19 de Maio de 2008 (ESESDJUÉ, 2008). Com o Despacho Reitoral 128/2009 de 22 de julho de 2009, cumprindo orientações hierárquicas, instalou-se em toda a
Universidade em setembro de 2009. Sob iniciativa do Gabinete de Sucesso Académico (GSA), começou também em outubro de 2009 a tutoria interpares na ESESDJ-UÉ.

O presente estudo tem como objetivo geral avaliar o regime de tutoria vigente na ESESDJUÉ, descrevendo-se a perspetiva dos docentes e discentes.

\section{Metodologia}

Trata-se de um estudo descritivo com abordagem quantitativa e qualitativa em amostra de conveniência. Os participantes recrutados enquadram-se em dois grupos: 1) os tutorantos, no caso os estudantes que frequentavam o período teórico, e 2) a totalidade dos docentes que à data se encontravam em exercício, no papel de tutores. Obteve-se permissão dos órgãos institucionais e dos participantes conforme Declaração de Helsinki de Ética em Pesquisa Envolvendo Seres Humanos (Williams, 2009).

\section{Tutorandos}

Participaram 146 alunos, dos quais 22 foram rapazes $(15.4 \%)$ e 121 raparigas (84.6\%), não tendo indicado o sexo. Têm idades entre 18 e 48 anos $(\mathrm{M}=21.9$; d.p. =4.64). Em tempo de aulas, a maior parte reside em casa dos pais $(\mathrm{N}=55 ; 37.9 \%)$, seguindo-se a co-habitação com colegas $(\mathrm{N}=40$; $27.6 \%)$ e quarto alugado $(\mathrm{N}=26 ; 17.9 \%)$. Com menor representação encontram-se os estudantes que vivem na Residência Universitária $(\mathrm{N}=15$; $10.3 \%)$, em casa própria ( $\mathrm{N}=7 ; 4.8 \%)$ e casa de familiares $(\mathrm{N}=2 ; 1.4 \%)$. A maior parte dos estudantes frequenta o $1^{\circ}$ ano $(\mathrm{N}=62 ; 42.5 \%)$, seguindo-se o $2^{\circ}$ ano $(\mathrm{N}=53 ; 36.3 \%)$ e no $3^{\circ}$ ano encontram-se $31(21.2 \%)$.

\section{Tutores}

Os tutores participantes foram 19. Em favor do anonimato, dadas as dimensões do corpo 
docente, não se colheram outros dados de identificação. $\mathrm{O}$ instrumento de recolha de informação para os estudantes, de autopreenchimento, foi construído com base em leituras sobre o assunto e tendo como orientação os domínios inscritos no Regulamento Específico do Curso de Licenciatura em Enfermagem, presentes no artigo $14^{\circ} . \mathrm{Na}$ primeira parte questionava-se, sobre a frequência dos episódios de tutoria, tempo despendido em cada um, suficiência/insuficiência dos contactos, regime obrigatório/facultativo, procura do tutor e conciliação com o quotidiano académico. Seguidamente, em grupos de variáveis apresentadas em escala tipo Likert com quatro pontos $(0=$ discordo totalmente a $4=$ concordo totalmente), exploravam-se aspetos tais como: 1) envolvimento do tutor no processo de desenvolvimento individual do estudante no contexto académico; 2) faceta do tutor como orientador do percurso de formação académica; 3) disponibilidade do tutor, e 4) atitude do tutor. Seguia-se outra secção sobre aspetos que mais preocupavam os estudantes na tutoria e a perceção de preocupação do tutor nesses mesmos episódios. Terminava-se com aspetos positivos e negativos da tutoria e sugestões de melhoria.

O questionário aplicado aos professores continha perguntas abertas e fechadas, referidas ao: 1) número de estudantes e frequência dos episódios de tutória; 2) tempo despendido; 3) adequação entre número de tutorandos e ano curricular; 4) assiduidade dos tutorandos aquando da convocação; 5) regime optativo/livre; 6) aspetos que preocupam o tutor e perceção de aspetos que preocupam os tutorandos; 7) aspetos positivos/negativos do exercício do papel de tutor; 8) sugestões para melhoria do papel de tutor, e 9) necessidade de formação.

Para a análise dos dados utilizou-se o Programa Statistical Package for the Social Sciences (SPSS), versão 16.

\section{Resultados \\ Frequência da tutoria na perspetiva dos tutorandos}

O tempo ocupado pelos episódios de tutoria varia entre 10 e 180 minutos, com média de 37.2 (d.p.=26.2). O número de episódios de tutoria mais representativo, são dois momentos de contacto com o tutor $(\mathrm{N}=45 ; 31 \%)$, referindo 49 estudantes três ou mais episódios (33.9\%).

Relativamente à frequência dos episódios de tutoria, a maioria dos estudantes $(\mathrm{N}=125 ; 88.3 \%)$ entende que o número de sessões foi o necessário e suficiente. A maior parte procurou a orientação do tutor para além das reuniões agendadas $(\mathrm{N}=81$; $55.9 \%$ ), teve facilidade em conciliar o seu trabalho com o horário das sessões $(\mathrm{N}=113 ; 78.5 \%)$ e considera que a tutoria deve ser facultativa $(\mathrm{N}=128$; $90.1 \%)$. A maior parte reconhece que tendo sido convocado pelo tutor, não compareceu em alguns episódios ( $\mathrm{N}=112 ; 77.2 \%)$.

\section{Perceção do papel do tutor}

Relativamente à opinião dos estudantes sobre o envolvimento do tutor no seu desenvolvimento pessoal, a maior representatividade, em todos os indicadores encontra-se na categoria concordo (tabela 1).

Questionaram-se os estudantes sobre o papel do tutor como orientador do percurso de formação académica. Nos indicadores, a maior representatividade encontra-se na categoria concordo, conforme se vê na tabela 2 .

No que se refere à disponibilidade percebida no tutor, os estudantes, exceto no indicador que avalia a compreensão no caso de adiamento por indisponibilidade do tutorando, encontra-sea maior representação na categoria concordo totalmente; as restantes respostas pontuam sobretudo na categoria concordo (tabela 3). 
Tabela 1. O tutor como orientador do processo de desenvolvimento

\begin{tabular}{|l|r|r|r|r|}
\hline \multicolumn{1}{|c|}{ Indicadores } & $\begin{array}{c}\text { Discordo } \\
\text { totalmente }\end{array}$ & Discordo & Concordo & $\begin{array}{c}\text { Concordo } \\
\text { totalmente }\end{array}$ \\
\hline $\begin{array}{l}\text { Partilho os meus objetivos de desenvolvimento } \\
\text { académico com o meu tutor }\end{array}$ & 2.07 & 6.21 & 47.6 & 44.1 \\
\hline $\begin{array}{l}\text { O meu tutor é a pessoa de referência nos problemas } \\
\text { pessoais de carácter académico }\end{array}$ & 5.6 & 13.9 & 50.0 & 30.6 \\
\hline $\begin{array}{l}\text { O meu tutor estimula a autoconfiança nas minhas } \\
\text { próprias capacidades }\end{array}$ & 2.1 & 15.9 & 42.0 & 40.0 \\
\hline $\begin{array}{l}\text { O meu tutor estimula a minha responsabilidade no } \\
\text { desenvolvimento académico }\end{array}$ & 2.1 & 9.7 & 46.9 & 41.2 \\
\hline
\end{tabular}

Tabela 2. O tutor como orientador do percurso de formação académica

\begin{tabular}{|l|r|r|r|r|}
\hline \multicolumn{1}{|c|}{ Indicadores } & $\begin{array}{c}\text { Discordo } \\
\text { totalmente }\end{array}$ & Discordo & Concordo & $\begin{array}{c}\text { Concordo } \\
\text { totalmente }\end{array}$ \\
\hline $\begin{array}{l}\text { O meu tutor estimula-me a analisar de forma crítica, } \\
\text { o meu percurso académico }\end{array}$ & 3.5 & 10.4 & 45.8 & 40.3 \\
\hline $\begin{array}{l}\text { O meu tutor define comigo metas ou objetivos reais } \\
\text { e exequíveis }\end{array}$ & 3.4 & 20.7 & 48.3 & 27.6 \\
\hline $\begin{array}{l}\text { O meu tutor orienta-me para atingir com qualidade } \\
\text { futuros papéis da profissão }\end{array}$ & 3.4 & 13.8 & 53.1 & \\
\hline $\begin{array}{l}\text { O meu tutor orienta-me para evitar riscos de insu- } \\
\text { cesso escolar }\end{array}$ & 2.1 & 13.1 & 51.0 & 33.8 \\
\hline
\end{tabular}

Tabela 3. Disponibilidade do tutor

\begin{tabular}{|l|r|r|r|r|}
\hline \multicolumn{1}{|c|}{ Indicadores } & $\begin{array}{c}\text { Discordo } \\
\text { totalmente }\end{array}$ & Discordo & Concordo & $\begin{array}{c}\text { Concordo } \\
\text { totalmente }\end{array}$ \\
\hline $\begin{array}{l}\text { O meu tutor mostra disponibilidade genuína para } \\
\text { atendimento tutorial programado }\end{array}$ & 1.4 & 8.3 & 47.6 & 42.8 \\
\hline $\begin{array}{l}\text { O meu tutor mostra disponibilidade genuína para } \\
\text { atendimentos não programados }\end{array}$ & 1.4 & 11.1 & 45.8 & 41.7 \\
\hline $\begin{array}{l}\text { O meu tutor mostra compreensão no caso de adia- } \\
\text { mento ou indisponibilidade minha, face a alteração } \\
\text { das sessões programadas de tutoria }\end{array}$ & 3.6 & 4.9 & 44.4 & \\
\hline $\begin{array}{l}\text { O meu tutor dá-me resposta atempada aos pedidos } \\
\text { de apoio que Ihe coloco }\end{array}$ & 1.3 & 4.8 & & 50.0 \\
\hline
\end{tabular}


Ao avaliar-se a atitude relacional do tutor através de cinco indicadores, exceto no que se refere ao apontar de fragilidades sem causar embaraço, a maioria refere a categoria concordo, os restantes pontuam sobretudo na categoria concordo totalmente (tabela 4).

\section{Dimensões do papel do tutor}

Realizou-se uma análise fatorial das variáveis. Após rotação varimax, observou-se que os estudantes identificam duas dimensões no papel do tutor (tabela 5). Uma dimensão com conotação de papel pedagógico, na medida da orientação do professor como facilitador da carreira do estudante face à profissão que se avizinha; uma dimensão com conotação relacional, na medida das interações inerentes à comunicação professor-aluno nas tutorias.

\section{Perspetiva dos professores}

O número de estudantes atribuídos a cada professor, em cada ano curricular (do $1^{\circ}$ ao $3^{\circ}$ ano) variou entre dois a cinco. O número total de tutorandos encontra-se entre dois e 11.
O exercício dos três momentos de tutoria, sobre a distribuição dos alunos nos vários semestres curriculares, foi cumprido pela maior parte dos professores, nos alunos do $1^{\circ}$ ano- $2^{\circ}$ semestre, $2^{\circ}$ ano- $1^{\circ}$ semestre e $3^{\circ}$ ano- $1^{\circ}$ semestre. Nos estudantes do $1^{\circ}$ ano- $1^{\circ}$ Semestre e $2^{\circ}$ ano- $2^{\circ}$ semestre, a maior parte dos professores não atingiu os três episódios tutoriais. Em média os professores ocupam 41.5 minutos (d.p.= 17.35) em cada episódio tutorial, variando numa amplitude entre 20 a 90 minutos. A maioria considera que duas sessões são as necessárias, qualquer que seja o semestre e ano curricular.

Os resultados mostram que para a maioria dos professores, os tutorandos solicitam orientação para além dos episódios de tutoria $(\mathrm{N}=14)$, que ocorreram algumas convocações sem comparecimento dos estudantes $(\mathrm{N}=10)$, que existe facilidade em conciliar o restante trabalho com o atendimento dos tutorandos $(\mathrm{N}=11)$. A preferência pelo regime livre/facultativo é indicada por quase todos os docentes $(\mathrm{N}=16)$.

Tabela 4. Atitudes do tutor na perspetiva dos tutorandos

\begin{tabular}{|c|c|c|c|c|}
\hline Indicadores & $\begin{array}{l}\text { Discordo } \\
\text { totalmente }\end{array}$ & Discordo & Concordo & $\begin{array}{l}\text { Concordo } \\
\text { totalmente }\end{array}$ \\
\hline O meu tutor tem uma postura amigável para comigo & 1.4 & 2.8 & 32.6 & 63.2 \\
\hline $\begin{array}{l}\text { O meu tutor aponta-me as fragilidades do } \\
\text { desempenho académico sem me envergonhar }\end{array}$ & 2.8 & 11.7 & 46.2 & 39.3 \\
\hline $\begin{array}{l}\text { O meu tutor dá-me oportunidade de exprimir as } \\
\text { minhas próprias opiniões }\end{array}$ & 0.7 & 4.2 & 31.9 & 63.2 \\
\hline $\begin{array}{l}\text { O meu tutor apoia-me nas situações académicas } \\
\text { emocionalmente críticas }\end{array}$ & 2.1 & 10.3 & 42.1 & 45.5 \\
\hline $\begin{array}{l}\text { O meu tutor dá-se reforço positivo pelos meus } \\
\text { sucessos }\end{array}$ & 1.4 & 8.5 & 44.0 & 46.1 \\
\hline
\end{tabular}




\begin{tabular}{|c|c|c|}
\hline & \multicolumn{2}{|c|}{ Componente } \\
\hline & 1 & 2 \\
\hline O meu tutor define comigo metas ou objetivos reais e exequíveis & 0.847 & \\
\hline O meu tutor estimula-me a analisar de forma crítica, o meu percurso académico & 0.841 & 0.314 \\
\hline O meu tutor orienta-me para atingir com qualidade futuros papéis da profissão & 0.826 & 0.348 \\
\hline O meu tutor estimula autoconfiança nas minhas próprias capacidades & 0.768 & 0.394 \\
\hline O meu tutor estimula a minha própria responsabilidade no desenvolvimento académico & 0.751 & 0.375 \\
\hline O meu tutor é a pessoa de referência para problemas pessoais de carácter académico & 0.689 & 0.418 \\
\hline O meu tutor orienta-me para evitar riscos de insucesso escolar & 0.659 & 0.488 \\
\hline Partilho os meus objetivos de desenvolvimento académico pessoal, com o meu tutor & 0.588 & 0.516 \\
\hline $\begin{array}{l}\text { O meu tutor mostra compreensão no caso de adiamento ou indisponibilidade minha, face a } \\
\text { alterações das sessões programadas de tutoria }\end{array}$ & & 0.852 \\
\hline O meu tutor dá-me resposta atempada aos pedidos de apoio que lhe coloco & & 0.826 \\
\hline O meu tutor tem uma postura amigável para comigo & & 0.741 \\
\hline O meu tutor mostra disponibilidade genuína para atendimentos não programados & 0.417 & 0.739 \\
\hline O meu tutor mostra disponibilidade genuína para atendimento tutorial programado & 0.417 & 0.718 \\
\hline O meu tutor dá-me oportunidade de exprimir as minhas próprias opiniões & 0.361 & 0.670 \\
\hline O meu tutor dá-se reforço positivo pelos meus sucessos & 0.548 & 0.647 \\
\hline O meu tutor aponta-me as fragilidades do desempenho académico sem me envergonhar & 0.507 & 0.605 \\
\hline O meu tutor apoia-me nas situações académicas emocionalmente críticas & 0.586 & 0.598 \\
\hline
\end{tabular}


Perceção dos professores sobre os assuntos que mais preocupam aos tutorandos

Numa questão aberta, solicitava-se aos professores a sua perceção sobre os assuntos (dois) mais problemáticos para os estudantes, organizando-se a sua categorização a partir da interpretação nas várias menções (quadro 1).
Opinião dos professores sobre os assuntos problemáticos dos seus tutorandos

Solicitou-se seguidamente aos professores que enunciassem dois assuntos mais preocupantes, relativamente aos estudantes que tem sob a sua tutoria (quadro 2).

\section{Quadro 1. Perceção dos professores sobre os maiores problemas dos tutorandos}

\begin{tabular}{|l|l|}
\hline \multirow{3}{*}{ Sobre-ocupação escolar } & $\begin{array}{l}\text { O trabalho escolar que é intenso/carga horária (1.Q1; 1.Q4) } \\
\text { Número/excesso de trabalhos solicitados/a elevada carga de trabalho/sobrecarga (1.Q2; 1.Q12; } \\
\text { 1.Q13; 1.Q41; 2.Q4; 2.Q15) } \\
\text { A dificuldade de se organizar para trabalhos/conciliação de trabalhos/ tempo para efetuar os } \\
\text { trabalhos (1.Q9; 1.Q16; 2.Q11) }\end{array}$ \\
\hline Avaliação curricular & $\begin{array}{l}\text { Avaliação nas disciplinas (1.Q3; 1Q7; 1.Q17; 1.Q19; 2.Q16) } \\
\text { O número/excesso de momentos de avaliação (1.Q5; 1.Q6; 1Q.18) } \\
\text { Número de frequências por disciplina (1.Q10) }\end{array}$ \\
\hline Curriculum escolar & $\begin{array}{l}\text { Plano de estudos Bolonha orientações contraditórias (1.Q.15) } \\
\text { Dificuldade em conciliar as matérias das várias UC (1.Q8) } \\
\text { Dificuldades em pstágios (2.Q7; 2.Q10) }\end{array}$ \\
\hline Organização escolar & $\begin{array}{l}\text { Desconhecimento sobre resultados avaliação contínua (2.Q2) } \\
\text { Momentos de avaliação, alguns não estão no planeamento (2.Q8) }\end{array}$ \\
\hline Outros & $\begin{array}{l}\text { Problemas nas relações entre colegas de turma (2.Q13) } \\
\text { Questões económicas (2.Q12) }\end{array}$ \\
\hline Interação nos pares & \begin{tabular}{l} 
Problemas na organização dos grupos de trabalho (2.Q19) \\
\hline
\end{tabular} \\
\hline
\end{tabular}




\section{Quadro 2. Opinião dos professores sobre os maiores problemas dos tutorandos}

\begin{tabular}{|c|c|}
\hline Aspetos curriculares & $\begin{array}{l}\text { Preocupação com sucesso/insucesso académico (1.Q2) } \\
\text { Não estarem ainda adaptados ao processo Bolonha (2.Q10) } \\
\text { Queixas relativas a docentes (2.Q12) } \\
\text { Apreensão de conteúdos nas unidades curriculares (2Q.4) }\end{array}$ \\
\hline $\begin{array}{l}\text { Bem-estar/bal-estar no } \\
\text { processo de ensino- } \\
\text { aprendizagem }\end{array}$ & $\begin{array}{l}\text { Nível de satisfação com o CLE (1.Q3) } \\
\text { Participação nas atividades da "vida" da escola (1.Q7) } \\
\text { Ansiedade perante avaliação (2.Q16) } \\
\text { A falta de ambição (1.Q5) } \\
\text { Pouca adaptação à vida escolar (1.Q9) } \\
\text { Relação entre colegas de turno/problemas entre alunos (2.Q13; 2Q.19) } \\
\text { Dificuldades de socialização (2.Q2) } \\
\text { Inibição dos alunos por obrigatoriedade de reuniões formais (2.Q8) }\end{array}$ \\
\hline $\begin{array}{l}\text { Gestão das tarefas } \\
\text { académicas }\end{array}$ & $\begin{array}{l}\text { Número elevado de trabalhos grupo (1.Q4) } \\
\text { Gestão/organização do tempo/carga de trabalho (1.Q6; 1.Q16; 1.Q18) } \\
\text { Dificuldade em conciliar horários de aulas, estágios tutorias (1.Q8) } \\
\text { A falta de tempo para marcação de sessões (1.Q10) } \\
\text { Dificuldade em organizar os tempos de estudo (1.Q13) }\end{array}$ \\
\hline Condições trabalho-estudo & $\begin{array}{l}\text { Dificuldade de conciliação da vida académica com a vida laboral (1.Q14) } \\
\text { Trabalhador estudante tem falta de tempo (1.Q15) }\end{array}$ \\
\hline Desenvolvimento pessoal & $\begin{array}{l}\text { Imaturidade dos alunos (2.Q14; } 2 . \mathrm{Q} 15) \\
\text { Pouco tempo para refletirem (2.Q18) }\end{array}$ \\
\hline Outros & $\begin{array}{l}\text { Surgirem problemáticas familiares (1.Q11; 1.Q12) } \\
\text { Problemas pessoais que interferem no processo de aprendizagem (1.Q19) }\end{array}$ \\
\hline
\end{tabular}

\section{Perceção dos professores sobre os benefícios da tutoria para o papel docente}

Solicitou-se aos docentes que apresentassem, dois aspetos positivos da tutoria para o exercício do papel docente. A categorização das menções encontra-se no quadro 3.

\section{Perceção dos professores sobre custos da tutoria para o papel docente Em questão aberta pedia-se aos docentes que}

identificassem dificuldades no exercício da tutoria, categorizando-se as menções conforme o quadro 4.

\section{Sugestões para melhoria da tutoria na perspetiva do docente}

Relativamente a sugestões para melhorar o regime de tutoria, os professores enunciam aspetos tais como: um menor número de tutorandos por docente, o regime facultativo após primeiro episódio de contacto, flexibilidade do agendamento e formação na área. A partilha de experiências com 


\section{Quadro 3. Benefícios da tutoria para o docente}

\begin{tabular}{|l|l|}
\hline $\begin{array}{l}\text { Promoção da interação } \\
\text { professor-aluno }\end{array}$ & $\begin{array}{l}\text { Maior comunicação/melhor relação professor-aluno (1.Q2; 2.Q9; 2.Q11) } \\
\text { Proximidade com os estudantes/seus pontos de vista/perspetivas (1.Q1; 1.Q3; 1.Q4; Q15; Q16; } \\
\text { 1.Q17; 2.Q2) } \\
\text { Melhor conhecimento dos alunos (1.Q10) }\end{array}$ \\
\hline Facilitação do processo \\
académico & $\begin{array}{l}\text { Conhecimento sobre as dificuldades dos alunos (1.Q8; Q14; 1.Q7; 1.Q18; 1.Q19) } \\
\text { Aproximação às necessidades e problemas dos alunos (1.Q11) } \\
\text { Mais conhecimento de como funciona todo o curso (2.Q3) } \\
\text { Adequar estratégia de ensino à realidade de Bolonha (2.Q4) } \\
\text { Conhecer a evolução do percurso do estudante (2.Q16) } \\
\text { Noção das disponibilidades dos alunos (2.Q17) }\end{array}$ \\
\hline Imagem do docente & $\begin{array}{l}\text { Valorização do papel do docente (2.Q10) } \\
\text { Reconhecimento dos estudantes (2.Q139) } \\
\text { Referência/identificação como pessoa de recurso (1.Q13) } \\
\text { Reflexão acerca do que realmente preocupa os alunos (2.Q15) }\end{array}$ \\
\hline Sem benefícios & \\
\hline & Não encontro nenhum benefício (1.Q12) \\
\hline
\end{tabular}

\section{Quadro 4. Custos da tutoria para o docente}

\begin{tabular}{|l|l|}
\hline Gestão docente & $\begin{array}{l}\text { Elevada carga/sobrecarga de trabalho (1.Q11; 1.Q13; Q14; Q15; Q18) } \\
\text { Ocupação/falta de tempo (1.Q12; Q16) } \\
\text { Ansiedade por não conseguirem responder ao número de sessões tutoriais (2.Q139) }\end{array}$ \\
\hline Ineficácia & $\begin{array}{l}\text { Incapacidade de resolver problemas (1.Q2) } \\
\text { Algumas reuniões com alguns tutorandos (2.Q3) }\end{array}$ \\
\hline Sem custos & $\begin{array}{l}\text { Não encontro custos (1.Q1) } \\
\text { Ao meu papel nenhum aspeto negativo (1.Q2) }\end{array}$ \\
\hline
\end{tabular}

outras instituições, reuniões e palestras são meios que os docentes referem como importantes para melhorar o seu desempenho.

\section{Discussão}

O regime instalado é do agrado de ambas partes, aspeto comprovado quando se constata que é sobreponível o entendimento e valorização, quanto à frequência e duração das tutorias. Assim, se por um lado é positiva aexistência de normativas institucionais relativamente ao regime das tutorias, na medida da instalação e regularização dos 
procedimentos, é também necessária alguma flexibilidade, ou não seja a tutoriaum processo que se enraíza em práticas concretas e contextos de cada instituição (Veiga Simão et al., 2008).

Constatando-se que a maior parte dos discentes da ESESDJ-UÉ procura os tutores para além das reuniões agendadas, tem facilidade de conciliação no quotidiano escolar, o absentismo às convocações do tutor é reduzido; mas que a grande maioria preferiria um regime facultativo, surgenos a ideia de que os discentes identificam o tutor como um recurso a utilizar de acordo com as suas próprias necessidades. Tais resultados podem ser interpretados à luz do desenvolvimento dos jovens universitários, a iniciar um compromisso de carreira, uma imagem identitária profissional. De facto, se por um lado a tutoria é uma referência e uma estratégia para vincular o estudante à formação, para apoiar o processo profissionalizante e permanência escolar (Riveroll, 2007; Barbosa, 2004), por outro, a orientação do educador tem data de caducidade, pois quanto maior o êxito, mais desnecessária torna-se com o suceder do tempo (Carbajo, 2004). Ou por outras palavras, se a tutoria docente é personalizada, dirigida à singularidade do estudante, fortalecendo-o para a utilização das suas potencialidades na solução dos problemas, maior serão a independência do estudante, as suas competências para as vivências académicas e tomada de decisões refletidas. Concorre esta ideia para a opinião dos docentes que consideram um menor número de episódios de tutória à medida que o estudante progride nos anos curriculares.

Os resultados referentes à perceção que os estudantes têm do papel do tutor transmitem a ideia de que o tutor apoia o estudante social e psicologicamente, tal como o é o seu papel (La Cruz, Campos e Hernández, 2006). Todos os anos saem das universidades indivíduos que percorreram o processo de ensino-aprendizagem sem problemas significativos, sabendo-se contudo que a entrada no ensino superior trás desafios e modificações ao quotidiano dos jovens (Duarte, 2008), nomeadamente àqueles, que deixando de coabitar com os pais, perdem no dia-a-dia, esta referência, gerando-se em alguns vulnerabilidade ao stress e ânimo depressivo (Nunes, 2006). Confrontam-se por vezes com o isolamento, com hábitos desconhecidos e partilha de espaços de maior intimidade se vivem com colegas/amigos ou em residências universitárias.

Estes indivíduos podem ainda estar expostos a práticas de suposta inclusão estudantil (praxe académica) que colidam com a sua forma de ser e estar. Têm que tomar decisões sobre organização pessoal nas atividades da vida diária e académica, o que para alguns menos preparados, pode ser demasiado exigente. Tal coloca-se com a cuidado no ensino de enfermagem, pois além destas modificações, algumas das temáticas e contextos de aprendizagem, colocam o jovem em situações emocionalmente exigentes. Contudo, se por um lado no processo da tutoria, o docente pode ser visto pelo estudante como uma figura de auxílio às exigências académicas, identificando situações de ansiedade, por outro lado, será necessário não confundir o papel de apoio tutorial, com a necessidade de recorrer à intervenção da psicologia clínica, encaminhando para os especialistas, nomeadamente para os gabinetes de apoio das universidades.

Os resultados referentes ao papel do tutor como orientador do percurso de formação, corroboram outros autores (La Cruz, Campos e Hernandez, 2006). O professor age como ligação entre o estudante e o plano de estudos, oferecendo-lhe assistência no planeamento de atividades académicas ao mesmo tempo que o socializa nos aspetos normativos da instituição. As interações próprias da orientação tutorial desenvolvem no estudante um compromisso de resultados positivos, atuando 
como estímulo para a motivação, para a construção de método de estudo, para a reflexão e autoconhecimento, gerando o pensar e o trabalhar por si mesmo (Barbosa, 2004).

Alguns estudos documentam que à entrada no ensino superior os estudantes têm fraca capacidade reflexiva e pouco desenvolvimento do pensamento crítico, aspetos que dificultam a adaptação e a prestação académicas (Duarte, 2008). De facto o papel do tutor como orientador do percurso pode estimular o estudante a tomar opções condizentes com os seus tempos, interesses, direitos e deveres, ajudando-o a evitar o insucesso e a perspetivar os desempenhos profissionais exigidos no futuro.

Apesar de que a metade dos professores reconhecem que nem todas as convocações para tutoria surtem efeito, os estudantes vêm disponibilidade dos docentes para o atendimento e os professores declaram essa mesma disponibilidade tanto para as reuniões agendadas como para as extraordinárias. A disponibilidade em horário é importante, na medida da rentabilização do quotidiano e respeito pelos papéis, mas é diferente da disponibilidade intrínseca do docente. Face à pessoa-aluno que orienta, a postura do professor para escutar as perspetivas do estudante é um fator fundamental para a aproximação. Se não existir verdadeira comunicação educativa, rapidamente o estudante o descobrirá (Carbajo, 2004).

Existe um leque de alternativas para conduzir as sessões tutoriais, porém só quando o tutor se torna um ouvinte atento, distingue as características dos vários tutorandos e a sua orientação se personaliza em diálogos com sentidos singulares. Ou não sejam o respeito pela integridade e personalidade do estudante, a relação de equidade e a tolerância, posturas éticas a ter em conta pelo professor (Riveroll, 2007). Contudo a tutoria não é uma relação entre iguais e a autoridade do docente deve ser marcada pelo professor e reconhecida pelo estudante, pois só assim se transmite a imagem de segurança e a figura de recurso; são na realidade atitudes que se desejam.

Os estudantes reconhecem nos tutores atitudes amigáveis, respeito pelas próprias ideias, reforço positivo e o apontar não ofensivo de fragilidades, concorrendo os resultados para a perspetiva de La Cruz, Campos e Hernandez (2006) que consideram nos comportamentos éticos dos tutores, a necessidade de fazer ver os erros aos estudantes sem os degradar na sua personalidade. Carbajo (2004) considera também absolutamente negativo a curiosidade e o "saque" de informações ao estudante. A qualidade da comunicação é fundamental no processo tutorial, transmitindo a atitude do professor o primeiro cartão de apresentação face ao estudante. Poderemos mesmo interrogar-nos se um dos motivos das ausências dos estudantes às convocatórias reside na atitude do tutor. Tal postura pode advir de muitos fatores, entre os quais, não só a indisponibilidade própria, pois nem todos os professores concordam com o regime tutorial, mas também a sobre-ocupação.

Os benefícios reconhecidos pelos docentes que exercem as tutorias radicam-se na facilitação do processo académico, na comunicação, no reconhecimento e valorização da imagem do professor. De facto, a maior comunicação com os estudantes pode abrir outros pontos de vista, facilitar a compreensão das perspetivas dos estudantes e assim atingirem-se melhores resultados na orientação e maior sucesso académico. Porventura constituir uma potencial fonte de desenvolvimento das competências relacionais de ajuda (Melo, 2005), numa profissão que como tal se reclama. É necessário porém ter em conta que os estudantes são diferentes e que a relação e comunicação que cada tutor estabelece com cada um dos tutorandos é única, devendo respeitar a individualidade de cada estudante, rejeitando padrões standartizados. Apesar das orientações básicas e tendo como objetivo comum o sucesso 
académico, cada estudante percorre a formação de maneira diferente. Residirá aqui a defesa de alguns dos professores participantes no estudo, de que após a primeira reunião, o regime deveria ser facultativo. Transparecem alguns custos para o docente. Acaso, o descontentamento provirá do não reconhecimento desta atividade na contabilização do trabalho docente. Tal é reconhecido por Lima (2006) que assim interpreta como menor dignificação de papel docente. Também Rué (2004, citado por Bornat, Castaño e Ruiz, 2007), considera que existe um desequilíbrio na atribuição de valor entre, por um lado o reconhecimento académico no papel de investigador e por outro, o valor atribuído à docência.

Justifica que a materialização do ensino de qualidade, no sentido do desenvolvimento de competências, necessita para que seja exequível, novos meios e modelos da atividade docente, assim como de novas formas de interação e de recursos.

A colocação de aspetos irresolúveis para o tutor é um facto apontado pelos docentes do estudo atual, sentindo que de alguma maneira a tutoria é ineficaz face a problemas de conflitos intra-institucionais, inter-pares, familiares e económicos declarados pelos estudantes das sessões tutoriais. Face a situações deste tipo, a maturidade e bomsenso do tutor deve imperar, não só procurando resolução e negociação, como encaminhando o estudante para recursos e serviços que a instituição escolar oferece.

Os estudantes reconhecem, de uma maneira geral, dois papéis essenciais nos tutores: papel relacional e papel pedagógico. Se por um lado os aspetos relacionais são algo desenvolvidos na formação dos próprios professores de enfermagem, pelas características da área de conhecimento, a pedagogia nem tanto. Mas as tutorias encerram em si mesmas, projetos pedagógicos dirigidos a cada um dos estudantes. Barbosa (2004) considera tambén que o projeto pedagógico é mais que um curriculum com exigência de conhecimentos, mas um processo de aprendizagem que permite ao aluno, como pessoa, desenvolver competências que determinam o perfil do cidadão com determinada profissão.

\section{Conclusão}

$\mathrm{Na}$ perspetiva dos estudantes, os resultados da avaliação do regime de tutoria mostram-se em termos gerais positivos. Os professores vêm a tutoria como fonte de orientação válida para o desenvolvimento dos estudantes. Em ambos grupos, alguns elementos, consideram preferível um regime facultativo. Ressalta na perceção dos estudantes, os papéis fundamentais dos tutores como promotores da relação e orientação pedagógica. Os maiores problemas identificados pelos professores residem na dificuldade dos estudantes em gerir os tempos, carga de trabalho e momentos de avaliação. A promoção da comunicação e a imagem do professor são benefícios identificados pelos docentes. Quanto a custos, sublinha-se o tempo e carga de trabalho que as tutorias implicam. Sugere-se a possibilidade de atividades no campo da pedagogia como forma de melhorar o desempenho docente. O regime tutorial da ESESDJ-UÉ, radica-se na prática concreta de dois anos de experiência e tende a orientar-se para as necessidades dos tutorandos, numa visão personalizada dos casos. 


\section{Referencias}

Ali, P. A. e W. Panther (2008), "Professional developmentand the role of mentorship", em Nursing Standart, vol. 22, núm. 42, pp. 35-39.

Barbosa, E. (2004), "A comunicação docente no sistema tutorial", dissertação de Mestrado em Educação, Universidade de Uberaba, Brasil.

Boronat, J., N. Castaño e E. Ruiz (2005), "La docência y la tutória en el nuevo marco universitário", em Reifop, vol. 19, núm. 8, pp. 69-74.

Carbajo, F. (2004),"La comunicación entre el professor-tutor y los alumnos. Reflexiones sobre la tutoría en centros estatales españoles", em Estudios sobre Educacion, núm. 7, pp. 129-142.

Carson, A. e R. Carnwell (2007), "Working in theorypractice gap: the lecturer practitioner's story", em Learning in Health and Social Care, vol. 6, núm. 4, pp. 220-230.

Comunidade Europeia (2005), "Diretiva 2005/36", em Jornal Oficial da União Europeia, pp. 22-142.

Duarte, I. (2008), "Transição e adaptação ao ensino superior artístico", em Sísifo. Revista de Ciências da Educação, vol. 7, pp. 29-38.

ESESDJUÉ (2008), Regulamento Específico do Curso de Licenciatura em Enfermagem, Évora, Universidade de Évora, Departamento de Enfermagem.

Gray, M. A. e L. Smith (2000), "The qualities of an effective mentor from the student nurse's perspective: findings from a longitudinal qualitative study", em Journal of Advanced Nursing, vol. 32, núm. 6, pp. 1542-1549.
La Cruz, G., T. Campos e L. Hernández (2006), "Modelo integrador de la tutoría", em Revista Mexicana de Investigación Educativa, vol. 11, núm. 31, pp. $1363-1388$.

Lima, L. (2006), "Bolonha à portuguesa", em A Pagina da Educação, http://www.apagina.pt/?aba=7\&cat= $160 \&$ doc $=11827 \& \mathrm{mid}=2$ [consulta: fevereiro 2010].

Melo, R. (2005), "Auto-conceito e desenvolvimento de competências relacionais de ajuda. Estudo com estudantes de enfermagem", em Revista Referência, II Serie, núm. 1, pp. 63-71.

Nunes, M. (2006), (In)Sucesso escolar no ensino superior: variáveis biopsicosociais, Lisboa, Associação dos Institutos Politécnicos do Centro.

Portugal (2006), "Decreto-Lei n ${ }^{\circ} 74 / 2006$ ", em Diário da República $1^{a}$ Serie, núm. 60, 24 de março, pp. 2 242-2 257.

Portugal (2008), "Decreto-Lei no 107/2008", em Diário da República $1^{a}$ Serie, núm. 121, 25 de junho, pp. 3 835-3 853.

Riveroll, B. (2007), "Proceso de construcción de un modelo de tutoría académica", em Separata Remo, vol. 1, núm. 11, pp. 1-4.

Veiga Simão, A., M. Flores, S. Fernandes e C. Figueira (2008), "Tutoria no ensino superior: concepções e práticas", em Sísifo. Revista de Ciências da Educação, núm. 7, pp. 75-87.

Williams, J. R. (2009), Manual de Etica Médica, 2a ed., http://www.wma.net/es/30publications/30eth icsmanual/pdf/ethics_manual_es.pdf [consulta: fevereiro 2010].

\section{Cómo citar este artículo:}

Sim-Sim, Maria-Margarida, Maria-do-Céu Marques, Maria-dos-Anjos Frade y Maria-Antónia Chora (2013), "Tutoria: perspetiva de estudantes e professores de enfermagem" en Revista Iberoamericana de Educación Superior (RIES), México, UNAM-IISUE/Universia, vol. IV, núm. 11, pp. 45-59, http://ries.universia.net/index.php/ries/article/ view/221 [consulta: fecha de última consulta]. 